\title{
AUSTRIAN HISTORY AWARD
}

The Austrian Institute is pleased to announce that the deadline for submitting manuscripts for the Austrian History Award has been extended to June 1, 1969.

The award of $\$ 1,000.00$-which is not to be confused with the annual Austrian Scholarship awarded by the Austrian Ministry of Education-is a one-time prize to be given for an unpublished manuscript dealing with the history of the Republic of Austria or of the German-speaking Cisleithanian parts of the Habsburg monarchy. Studies focused on problems and institutions of the Habsburg monarchy as a whole as well as biographies of personalities of empire-wide significance may also be submitted. With this award the anonymous donor wishes to stimulate American research in the field.

To qualify for the contest, a manuscript must be written by an American author. It should be based on original research, fully documented, and not less than 25,000 words in length. Dissertations will only be considered after they have been formally approved by the author's sponsoring professors. The manuscript must be unpublished at the time the competition closes on June 1, 1969. Both text and footnotes should be double spaced.

Members of the panel of judges are Prof. Robert A. Kann, of Rutgers University (chairman); Prof. R. John Rath, of Rice University; Dr. E. Wilder Spaulding, of Washington, D.C.; and the Director of the Austrian Institute Dr. Gottfried Heindl. Inquiries should be directed to the Austrian Institute.

Manuscripts are to be mailed to the Austrian Institute, 11 East 52 Street, New York, N. Y. 10022, not later than June $1,1969$.

\section{AUSTRIAN MINISTRY OF EDUCATION SCHOLARSHIP}

The Austrian Ministry of Education will again grant a limited number of scholarships for the academic year 19691970. One or more of these scholarships can be awarded to American students now working on a doctoral dissertation or on another research project in the field of Austrian history. These scholarships carry a monthly stipend of 2,600 schilling (approximately $\$ 100.00$ ). They are not to be used to supplement a stipend received from another scholarship or fellow- 
ship. Holders of these scholarships are expected to be in residence in an Austrian university. Married students are not excluded from consideration, but the grant itself covers only the cost of tuition and maintenance of a single person. Candidates wishing to apply for this scholarship should send a letter of application, together with letters of recommendation and other supporting material, including an outline of their research project, directly to Professor Robert A. Kann, Department of History, Rutgers University, New Brunswick, N. J. 08903, before December 1, 1968.

Rutgers University

ROBERT A. KANN 